\title{
Gerakan Pemuda sebagai Basis Promotif dan Preventif Pra Lansia dan Lansia
}

\author{
Farindira Vesti Rahmasari*, Denny Anggoro P, Fadli Mahjud, \\ Latifah Mutiara Haryanto \\ Program Studi Pendidikan Dokter,Fakultas Kedokteran dan Ilmu Kesehatan \\ Universitas Muhammadiyah Yogyakarta \\ email: farindira.vesti@umy.ac.id
}

\begin{abstract}
Non-communicable diseases (NCDs) such as heart disease, stroke, cancer, diabetes, and chronic obstructive pulmonary disease are the causes of death within nearly $75 \%$ in the world (WHO, 2018). In 2012, there were 29,546 cases of hypertension and 7,434 cases of diabetes happened in DIY (Daerah Istimewa Yogyakarta). Based on Basic Health Research (Rikesdas), the prevalence of NCD increased from 2007 to 2013 and is expected to continue. NCD risk factors include unhealthy dietary habit, lack of physical activity, consumption of alcoholic beverages, and smoking. People with obesity, high blood pressure, high blood sugar level, high cholesterol, and a history of NCD in older people are at high risk of developing NCD.

One of the effort in controlling NCD is prevention such as periodic health checking. NCD risk factors examination can be done through NCD Integrated Development Post (Posbindu) in the village. The results indicate that the average value before being educated is 44,17 , while after being educated is 68,33. There was an increase of 24,16. These results indicate that the correlation between two variables yields 0.183 with probability value below 0.05 , which states that the correlation between the previous and final values after educated is weak and there is obvious correlation. It is concluded that cadres' knowledge and skill can be improved by training and continued by monitoring the cadre's skills observation field
\end{abstract}

Keywords: cadre, training, posbindu, preventive

\begin{abstract}
Abstrak
Penyakit tidak menular (PTM) seperti penyakit jantung, stroke, kanker, diabetes, dan penyakit paru obstruktif kronis merupakan penyebab kematian hampir $75 \%$ di dunia (WHO, 2018). Pada tahun 2012 di DIY, terdapat 29.546 kasus hipertensi dan 7.434 kasus diabetes. Berdasarkan Riset Kesehatan Dasar (Rikesdas), prevalensi PTM meningkat dari tahun 2007 sampai 2013 dan diperkirakan akan terus berlanjut.Faktor risiko PTM meliputi pola makan yang tidak sehat, kurangnya aktivitas fisik, konsumsi minuman beralkohol, dan merokok. Orang dengan obesitas, tekanan darah tinggi, kadar gula darah tinggi, kolesterol tinggi, dan riwayat PTM pada orang tua berisiko tinggi terkena PTM.

Salah satu upaya dalam pengendalian PTM adalah tindakan pencegahan. Salah satu bentuk pencegahannya yakni dengan mengecek kesehatan secara berkala. Pemeriksaan faktor risiko PTM dapat dilakukan melalui Pos Pembinaan Terpadu (Posbindu) PTM yang ada di desa/kelurahan. Hasil tersebut menunjukkan bahwa nilai rata-rata sebelum dilakukan edukasi adalah 44,17, sedangkan nilai rata-rata setelah dilakukan edukasi adalah 68,33. Terdapat peningkatan sebanyak 24,16. Hasil tersebut menunjukkan bahwa korelasi kedua variabel menghasilkan angka 0,183 dengan nilai probabilitas 0,008 yang berarti nilai probabilitas dibawah 0,05 yang menyatakan bahwa korelasi antara nilai sebelum dan nilai sesudah edukasi adalah sangat lemah dan terdapat perbedaan yang nyata antara nilai rata-rata sebelum dan nilai rata-rata sesudah pemberian edukasi. Disimpulkan bahwa pengetahuan dan keterampilan kader posbindu dapat ditingkatkan melalui pelatihan yang dilanjutkan dengan monitoring lapangan observasi keterampilan kader.
\end{abstract}

Kata Kunci: kader, pelatihan, posbindu, preventif 


\section{PENDAHULUAN}

Seluruh kematian akibat PTM terjadi pada orang-orang berusia kurang dari 60 tahun, 29\% di negara-negara berkembang, sedangkan di negara-negara maju sebesar 13\%.Proporsi penyebab kematian PTM pada orang-orang berusia kurang dari 70 tahun, penyakit kardiovaskular merupakan penyebab terbesar (39\%), diikuti kanker (27\%), sedangkan penyakit pernafasan kronis, penyakit pencernaan dan PTM yang lain bersama-sama menyebabkan sekitar (30\%) kematian, serta $4 \%$ kematian disebabkan diabetes.Berdasar Riset Kesehatan Dasar (Riskesdas) pada tahun 2013, 69,6\% dari kasus diabetes melitus dan $63,2 \%$ dari kasus hipertensi masih belum terdiagnosis.Keadaan ini mengakibatkan penanganan menjadi sulit, terjadi komplikasi bahkan berakibat kematian lebih dini (Purdiyani F, 2016)

Penyakit kronis yang tidak ditularkan atau lebih dikenal dengan penyakit tidak menular (PTM) menjadi tren penyakit saat ini. Menurut WHO pada tahun 2016, PTM yang meliputi penyakit jantung, stroke, kanker, diabetes, dan penyakit paru obstruktif kronis merupakan penyebab kematian hampir $75 \%$ di dunia. Pada tahun 2012 di Daerah Istimewa Yogyakarta (DIY), terdapat 29.546 kasus hipertensi dan 7.434 kasus diabetes. Kedua penyakit ini masuk dalam 10 besar penyakit berdasarkan Survailans Terpadu Penyakit (STP) Puskesmas. Dari data laporan rumah sakit di DIY pada tahun 2011, 7 di antara 10 penyebab kematian di rumah sakit adalah PTM. (Dinas Kesehatan Yogyakarta, 2011).

Faktor risiko PTM berkaitan erat dengan pola hidup. Berdasarkan laporan WHO tahun 2011, empat faktor utama penyebab PTM adalah makanan tidak sehat, kebiasaan merokok, penggunaan alkohol, gaya hidup tidak sehat seperti aktivitas fisik yang kurang. Selain itu, tingkat kepedulian masyarakat akan kesehatan yang masih rendah juga menjadi penyebab tingginya kejadian PTM. Karena sifatnya kronis dan baru muncul gejala fisik setelah terjadi komplikasi, PTM sering dianggap sebelah mata. Orang dengan obesitas, tekanan darah tinggi, kadar gula darah tinggi, kolesterol tinggi, dan riwayat PTM pada orang tua berisiko tinggi terkena PTM (Depkes,2015).

Meningkatnya kejadian PTM menambah beban penyakit di Indonesia. Beban yang dimaksud meliputi kerugian finansial, angka morbiditas atau keadaan sakit yang tinggi, dan mortalitas atau angka kematian yang tinggi. Menyikapi fenomena ini, pemerintah mencanangkan Gerakan Masyarakat Hidup Sehat (Germas) yang mengedepankan upaya promotif dan preventif. Program Germas diimplementasikan dalam bentuk CERDIK: Cek kesehatan secara berkala, Enyahkan asap rokok, rajin beraktivitas fisik, diet yang sehat dan seimbang, istirahat yang cukup dan kelola stress. Salah satu bentuk pencegahannya yakni dengan mengecek kesehatan secara berkala.

Organisasi kesehatan dunia (WHO) telah merekomendasikan agar memusatkan penanggulangan PTM melalui tiga komponen utama, yaitu surveilans faktor risiko, promosi kesehatan, dan pencegahan melalui inovasi dan reformasi manajemen pelayanan kesehatan. Pengendalian PTM di Indonesia terdapat dalam UU RI No.36 tahun 2009 tentang penyakit tidak menular yang berisi upaya yang dilakukan dalam pengendalian penyakit tidak menular, yaitu pencegahan, pengendalian, penanganan, dan akibat yang ditimbulkan dari suatu penyakit (Jayusman,TAI \& Widiyarta,A, 2017) 
Tabel.1 Permasalahan dan Pemecahan Masalah

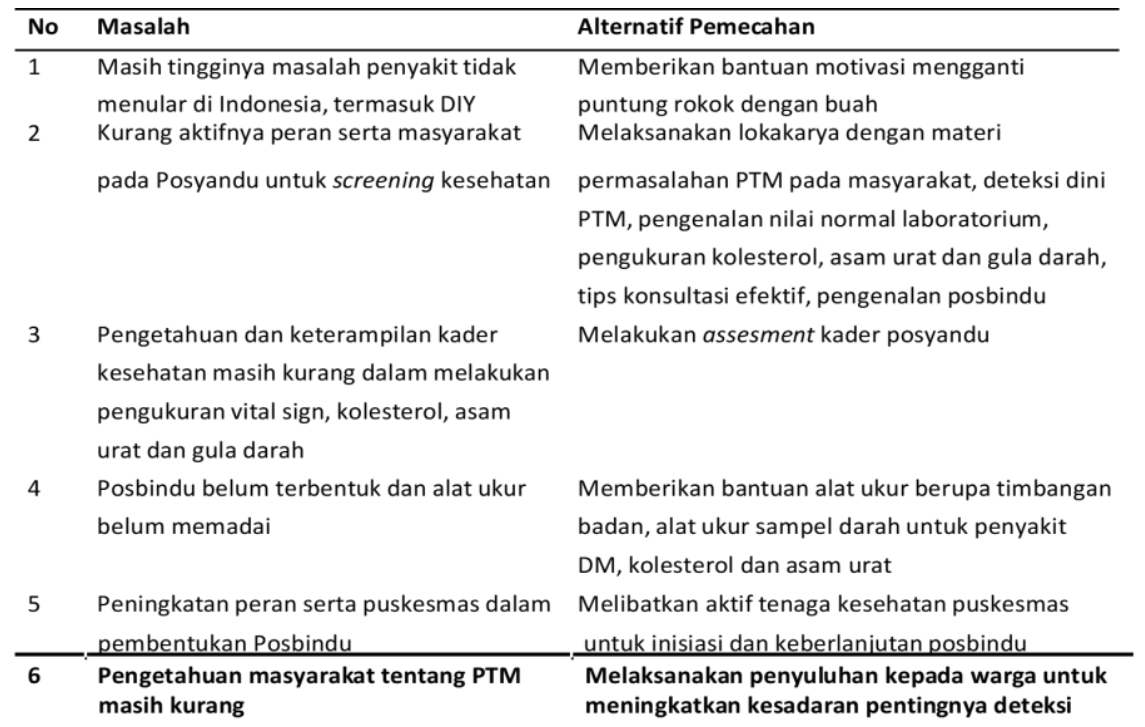

Tujuan kegiatan pengabdian masyarakat ini adalah meningkatkan upaya pencegahan dan deteksi dini PTM serta mencegah komplikasi lanjutan di Dukuh Donotirto serta terbentuknya Posbindu kemitraan UMY dengan masyarakat. Dengan demikian, faktor resiko PTM dapat terdeteksi dan tertangani sejak awal sehingga nantinya dapat menjadi generasi yang cerdas, sehat dan tetap produktif. Berdasarkan permasalahan yang telah dijabarkan di atas, maka solusi yang ditawarkan pada kegiatan pengabdian masyarakat ini bisa dilihat seperti yang tercantum pada Tabel 1.

\section{METODE PENGABDIAN}

Posbindu PTM ini adalah program berbasis masyarakat, sehingga pendekatan partisipatif akan digunakan semaksimal mungkin. Peran masyarakat akan dikembangkan sejak dari perencanaan bahkan dari penggalangan kesadaran akan masalah, penggalian ide dan akhirnya penyusunan bersama konsep dan rencana aksinya. Tokoh masyarakat dan pemuda yang potensial akan dilibatkan sejak dari perencanaan dan masyarakat juga akan dilibatkan dalam pelaksanaan kegiatan sebagai kader atau pekerja sosial. Pada kegiatan pengabdian ini juga dilakukan penelitian menggunakan metode pendekatan cross sectional. Penelitian ini adalah penelitian kuantitatif dengan jenis penelitian adalah penelitian survei.

Rancangan pada penelitian ini adalah penelitian analitik. Penelitian ini menggunakan disain Quasi eksperimental yang hanya menggunakan kelompok studi tanpa menggunakan kelompok kontrol, serta pengambilan responden tidak dilakukan randomisasi. Penelitian dilakukan terhadap 14 kader posbindu yang mendapatkan materi pelatihan deteksi dini PTM, pencegahan dan edukasi yang baik dan benar. Kader posbindu yang dilatih adalah kader posbindu dari posyandu lansia dan balita yang aktif dan belum pernah mengikuti pelatihan PSG lansia. Variabel bebas penelitian adalah tingkat pengetahuan dan variabel terikatnya edukasi kepada kader. Lokasi penelitian di dukuh Donotirto.

Instrumen yang digunakan berupa Kuesioner/ panduan wawancara, alat tulis dan accu check untuk kolesterol, gula darah dan asam urat.

Tahapan metode pelaksanaan :

1. Tahapan Perencanan Partisipatif

Tim Pengabdian bersama mitra, yaitu kader Posyandu dan Tokoh masyarakat mengadakan mjusyawarah secara informal dilanjutkan dengan penyusunan rencana kegiatan dan proposal kegiatan 
2. Tahapan Asesmen Kegiatan Posyandu

a. Tim Pengabdian berkunjung ke puskesmas dan menghadiri kegiatan Posyandu, ditemukan 10 besar penyakit yang masih menjadi perhatian dan belum adanya posyandu yang khusus menitikberatkan pada pengendalian faktor resiko PTM melalui pengendalian masyarakat.

b. Penilaian tingkat pengetahuan dan praktik deteksi dini dengan menggunakan alat ukur glukosa, kolesterol dan asam urat dengan pemantauan dari petugas kesehatan

3. Tahapan Lokakarya / ToT

Lokakarya merupakan forum pembekalan materi teori dan diskusi interaktif disertai praktik dan simulasi kepada para kader.

4. Tahap pemberian bantuan alat ukur deteksi dini PTM berupa Accu Check merupakan kombinasi alat ukur kadar kolesterol, gula darah dan asam urat serta tensimeter digital.

5. Tahap peningkatan pengetahuan masyarakat untuk memberi wawasan kepada masyarakat juga mengenai faktor resiko sehungga akan lebih berwaspada untuk menjaga kesehatannya.

6. Jalan Sehat bersama untuk membudayakan gaya hidup sehat. menjelaskan pendekatan, rancangan kegiatan, ruang lingkup atau objek, bahan dan alat utama, tempat, teknik pengumpulan data, definisi operasional variabel penelitian, dan teknik analisis.

\section{HASIL DAN PEMBAHASAN}

Hasil tersebut menunjukkan bahwa korelasi kedua variabel menghasilkan angka 0,183 dengan nilai probabilitas dibawah 0,05 yang menyatakan bahwa korelasi antara nilai sebelum dan nilai sesudah edukasi adalah lemah dan terdapat hubungan yang bermakna. Hal ini dimaksudkan agar kegiatan peningkatan pengetahuan, pemahaman materi serta keterampilan dari para kader dapat lebih di asah dengan pertemuan maupun diskusi lanjutan oleh Pembina setempat dapat dilakukan oleh petugas puskesmas, petugas kesehatan setempat maupun tokoh masyarakat.

Tabel 1. Hasil Paired Samples Test Sebelum dan Setelah Edukasi pada Kader Posyandu Dusun Donotirto, Kasihan , Bantul

\begin{tabular}{|c|c|c|c|c|c|c|c|c|}
\hline & \multicolumn{5}{|c|}{ Paired Differences } & & \\
\hline & & \multirow{2}{*}{ Mean } & \multirow{2}{*}{$\begin{array}{l}\text { Std. } \\
\text { periation }\end{array}$} & \multirow{2}{*}{$\begin{array}{l}\text { Std. Error } \\
\text { Mean }\end{array}$} & \multicolumn{2}{|c|}{$\begin{array}{l}95 \% \text { Confidence Interval } \\
\text { of the Difference }\end{array}$} & & \\
\hline & & & & & Lower & Upper & & \\
\hline \multirow{2}{*}{ Pair 1} & $\begin{array}{l}\text { SCORE PRETEST - } \\
\text { SCORE POSTEST }\end{array}$ & -24.167 & 25.746 & 7.432 & -40.525 & -7.808 & -3.252 & 11.008 \\
\hline & Pos & \multicolumn{7}{|c|}{ Pembinaan } \\
\hline
\end{tabular}

(POSBINDU) PTM adalah peran serta masyarakat dalam melakukan kegiatan deteksi dini dan monitoring terhadap faktor risiko PTM serta tindak lanjutnya yang dilaksanakan secara terpadu, rutin, dan periodik. Pelaksanaan tindak lanjutnya dalam bentuk konseling dan rujukan ke fasilitas pelayanan kesehatan dasar. Upaya pe- ngembangan program POSBINDU PTM sedang gencar dilakukan, dan harapan ke depan POSBINDU PTM dapat dijadikan "kendaraan program" pengendalian penyakit tidak menular di masyarakat Agar upaya ini dapat berjalan dengan baik, benar, dan tepat sasaran perlu disusun satu pedoman untuk melaksanakannya sehingga implementasi dari POSBINDU PTM mempunyai daya ungkit dalam pengendalian faktor risiko PTM (Panduan POSBINDU PTM, Kemenkes 2012).

Kader adalah tenaga suka rela yang dipilih oleh dan dari masyarakat yang bertugas di masyarakat. Dalam kegiatan posyandu, kader memegang peranan penting, selain sebagai pelaksana kegiatan posyandu (administrator) dan memberikan penyuluhan (edukator), kader juga menggerakkan keaktifan ibu yang mempunyai balita untuk datang ke posyandu (motivator).

Informasi akan memberikan pengaruh pada pengetahuan seseorang. Pengetahuan seseorang akan meningkat meskipun dengan tingkat pendidikan yang rendah apabila ia mendapatkan informasi 
yang baik dari berbagai media misalnya televisi, radio atau surat kabar, atau orangorang disekililingnya. Maka hal itu akan dapat meningkatkan pengetahuan seseorang.Informasi sangat berperan penting untuk seseorang mengetahui pengetahuan tertentu. semakin banyak seseorang memperoleh informasi maka semakin baik pula pengetahuan seseorang. Informasi dianggap sebagai pemberitahuan mengenai masalah yang penting (Rahayu NF\& Fuadah DZ, 2018). Hasil penelitian ini menunjukkan perbaikan tingkat pengetahuan kader mengenai PTM yaitu nilai rata-rata sebelum dilakukan edukasi adalah 44,17, sedangkan nilai rata-rata setelah dilakukan edukasi adalah 68,33. Terdapat peningkatan sebanyak 24,16.

Proses penggunaan atau pemanfaatan sarana kesehatan oleh masyarakat atau konsumen yang baik akan dimulai dari pengetahuan yang baik pula. Pentingnya manfaat-manfaat kesehatan, seperti keyakinan bahwa pelayanan kesehatan dapat menolong proses penyembuhan penyakit. Pernyataan tersebut semakin menegaskan bahwa usia, tingkat pendidikan dan informasi seseorang mempengaruhi tingkat pengetahuan seseorang tentang POSBINDU PTM dan dalam memanfaatkan pelayanan POSBINDU PTM, dipengaruhi oleh usia, dan pekerjaaan. Sehingga seseorang berpeluang besar dalam memanfaatkan pelayanan POSBINDU PTM dengan optimal (Rahayu NF\& Fuadah DZ, 2018)

Berdasarkan penelitian (Purdiyani F, 2016) terdapat hubungan antara dukungan kader kesehatan dengan pemanfaatan Posbindu PTM oleh wanita lansia.

Hasil penelitian yang dilakukan oleh (Kiring,RP., Imi ,B., Arifin S., 2015) secara simultant sikap, motivasi, penghargaan dan desain pekerjaan berhubungan dengan kinerja kader Posbindu PTM di Posbindu Kota Banjarmasin. Hasil Nagelkerke R Square yang didapatkan sebesar 0,891 yang menunjukkan bahwa kemampuan sikap, motivasi, penghargaan dan desain pekerjaan secara bersama-sama dalam menjelaskan kinerja kader Posbindu PTM sebesar $89,1 \%$.

Tabel 2. Hasil Score Penilaian Pretes dan Postest Kader Posyandu mengenai Pemahaman PTM di Dusun Donotirto,Kasihan, Bantul.

\begin{tabular}{|c|c|c|c|c|}
\hline No & NAMA & $\begin{array}{c}\text { SCORE } \\
\text { PRETEST }\end{array}$ & $\begin{array}{c}\text { SCORE } \\
\text { POSTEST }\end{array}$ & KETERANGAN \\
\hline 1 & Sumiatun & 70 & 60 & Ada penurunan \\
\hline 2 & Niyati & 70 & 80 & Ada peningkatan \\
\hline 3 & Suci Wahyuni & 60 & 90 & Ada peningkatan \\
\hline 4 & Asih Caca & 60 & 90 & Ada peningkatan \\
\hline 5 & Parmi & 40 & 90 & Ada peningkatan \\
\hline 6 & Suliyati & 40 & 20 & Ada penurunan \\
\hline 7 & Lastri & 40 & 80 & Ada peningkatan \\
\hline 8 & Anti & 40 & 40 & Tetap \\
\hline 9 & Rina & 40 & 60 & Ada peningkatan \\
\hline 10 & Puji & 30 & 60 & Ada peningkatan \\
\hline 11 & Asih & 20 & 60 & Ada peningkatan \\
\hline 12 & Sutrini & 20 & 90 & Ada peningkatan \\
\hline 13 & Ponirah & - & 4075 & - \\
\hline 14 & Supiah & - & 1698 & - \\
\hline
\end{tabular}

Dari 14 kader yang menghadiri pelatihan didapatkan :

1. 9 orang yang mengalami peningkatan setelah diberikan materi

2. 2 orang yang menglami penurunan setelah diberikan materi

3. 1 orang yang tetap setelah diberikan materi

4. 2 orang yang tidak bisa di tarik kesimpulan karena terdapat 2 orang yang terlambat.

\section{KESIMPULAN}

Telah dilaporkan kegiatan pengabdian masyarakat berupa lokakarya, pemberian bantuan alat ukur dan bantuan makanan tambahan serta pendampingan lanjut dalam bentuk forum komunikasi "posbindu donotirto". Kegiatan ini bertujuan untuk pencegahan PTM dan inisiasi pembentukkan posbindu PTM dasar di dukuh Donotirto. Kecamatan Kasihan, Bantul, Yogyakarta. Forum komunikasi menunjukkan keaktifan kader di lokasi pengabdian selama dan pasca kegiatan pengabdian. Peningkatan derajat kesehatan dapat diupayakan melalui peningkatan pemanfaatan pelayanan POSBINDU PTM di setiap wilayah binaan 
puskesmas, selain itu peran serta tenaga kesehatan serta kader sangat diperlukan untuk lebih mensosialisasikan tentang POSBINDU PTM ke masyarakat khususnya penderita penyakit tidak menular.

\section{UCAPAN TERIMA KASIH}

Terima Kasih kami haturkan kepada kader posyandu lansia dan balita dukuh Donotirto dan Puskesmas Kasihan 1 Bantul atas peran serta aktifnya dalam mensukseskan pelaksanaan Posbindu PTM. LP3M UMY atas dukungan pendanaan demi lancarnya program pengabdian kemitraan masyarakat.

\section{DAFTAR PUSTAKA}

[1]. Profil Kesehatan Provinsi D.I Yogyakarta, Dinas Kesehatan Yogyakarta, Indonesia, 2011, pp. 2683.

[2]. Profil Kesehatan Indonesia, Depkes RI, Indonesia,2015,pp.1-115.

[3]. Jayusman TAI, Widiyarta A, "Efektivitas Program Pos Pembinaan Terpadu (POSBINDU) Penyakit Tidak Menular (PTM) di Desa Anggaswangi Kecamatan Sukodono Sidoarjo," Jurnal Dinamika Governance. vol.7, no.2, pp. 178-83, 2017.

[4]. Wahyutomo, "Hubungan Karakteristik Dan Peran Kader Posyandu Dengan Pemantauan Tumbuh Kembang Balita Di Puskesmas Kalitidu - Bojonegoro," dissertation, Dept, Fam, Med., Universitas Sebelas Maret Surakarta., Surakarta, Indonesia, 2011.

[5]. Panduan POSBINDU PTM, Kemenkes RI, Indonesia, 2012, pp. 7 9.

[6]. Fatmah, "Pengaruh Pelatihan pada Peningkatan Pengetahuan dan
Keterampilan Teknis Penyuluhan Obesitas dan Hip'ertensi Kader Posbindu Kota Depok," Makara Seri Kesehatan. vol.17, no.3, pp. 49-54, 2013.

[7]. Rahayu. NF and Fuadah. DZ, "Pemanfaatan Pos Pembinaan Terpadu (POSBINDU) Penyakit Tidak Menular (PTM) Pada Penderita Hipertensi," Jurnal Ners dan Kebidanan, vol.5, No.1, pp.120-128, 2018.

[8]. Fatmah, and Y. Nastution, "Peningkatan Pengetahuan dan Keterampilan Kader Posbindu dalam Pengukuran Tinggi Badan Prediksi Lansia, Penyuluhan Gizi Seimbang dan Hipertensi Studi di Kecamatan Grogol Petamburan, Jakarta Barat"” Media Medika Indonesiana, vol. 46, no.1, pp.61-68, 2012.

[9]. F. Purdiyani, "Pemanfaatan Pos Pembinaan Terpadu Penyakit Tidak Menular (Posbindu Ptm) Oleh Wanita Lansia Dalam Rangka Mencegah Penyakit Tidak Menular Di Wilayah Kerja Puskesmas Cilongok 1," Jurnal Kesehatan Masyarakat (e-Journal), vol. 4, no. 1, pp. 470-480, 2016.

[10]. RP. Kiting, B. Ilmi, and S. Arifin, "Faktor Yang Berhubungan Dengan Kinerja Kader Posbindu Penyakit Tidak Menular," Jurnal Berkala Kesehatan.vol.4, no.1,pp. 106-114, 2015. 
